\title{
Study of the Formability of Laminated Lightweight Metallic Materials
}

\author{
Claudia Girjob ${ }^{1, *}$, and Gabriel Racz ${ }^{1}$ \\ ${ }^{1}$ Lucian Blaga Univerity of Sibiu, 10 B-dul Victoriei, Sibiu, Romania
}

\begin{abstract}
The main objective of this work was to test the formability of laminated materials. Laminated materials are considered a good choice when parts with reduced weight are considered. Thus, a laminated material, aluminum - polypropylene - aluminum (Al-PP-Al), as sheet $1.2 \mathrm{~mm}$ and $1.4 \mathrm{~mm}$ thickness was used. Before processing the material by means of unconventional plastic deformation, its formability was determined by running the Nakajima test. After obtaining the forming limit curves, the material was machined by means of incremental forming.
\end{abstract}

\section{Introduction}

At present days, there is a continued interest in using composite materials made by means of laminated layers for building structural elements for the automotive industry. These materials are lightweight metallic materials [1]. A widespread use as composites is reported for aluminum-plastic-aluminum, polymer-steel plastic and steel-polymer-steel.

These materials possess some significant advantages, because they can replace more expensive ones, while preserving the qualities of the final product, or even increasing the overall performance and lifespan of it.

Laminated workpieces made of metal-polymer-metal layers show a good machinability by means of plastic deformation, which is considered similar with the one of workpieces made of usual metallic materials. The work presented in [2] has experimentally proven that the workpieces made of steel-polypropylene-steel layers shows a better formability compared with AA5128 aluminum layer. Some specific characteristics for plastic deformation processes, such as the limiting drawing ratio were found to be better or at least equal for some composite materials than the ones of conventional materials used for manufacturing body parts within the automotive industry [3]. The work presented in [4] has proven that the forming limit for laminated materials composed of aluminum - polymeraluminum layers is heavily influenced by the size of the aluminum layers.

To assess the machinability by means of plastic deformation processes, together with their mechanical proprieties, a series of tests are unfolded, such as uniaxial tensile test, bending test and shear tests [5].

Laminated materials were targeted lately for manufacturing parts with reduced of small weights. Aside of automotive industry, prosthetic devices can also be produced using these materials as workpieces [6].

${ }^{*}$ Corresponding author: claudia.girjob@ulbsibiu.ro 
In order to machine parts made of composite materials, unconventional technologies are often the best choice [7]. Incremental forming, due to its high degree of flexibility, has been proven itself as machining process, mainly when producing parts in small batches or even prototypes [8-9]. One of the requirements when machining by incremental forming is that the formability of the workpiece must be known, consequently some specific tests, such as Nakajima test must be unfolded, to determine the forming limit curves of the processed material [10].

Incremental forming may be performed using either CNC multi-axis milling machines, or serial industrial robots as technological equipment. Preventive measures should be taken, because technological forces cannot be accurately predicted and could exceed the allowable forces on the CNC machines or robots. There are some research works reported in the literature with regards of how to calculate the size of the technological forces which occur during the incremental forming process [11-13].

A literature survey reports in [14] a research work which considered composite material mild steel-polypropylene-mild steel aluminum-polypropylene-aluminum respectively as workpiece for manufacturing parts by incremental forming. The experimental tests had shown good results with regards of formability, allowing to be machined without the occurrence of cracks.

\section{Materials used for researches}

For the approach presented here, test samples from aluminum - polypropylene - aluminum (Al-PP-Al) laminated material were used. The workpieces were chosen as sheets of $1.2 \mathrm{~mm}$ and $1.4 \mathrm{~mm}$ thickness. The workpiece consists of two layers of aluminum (AA5182) of 0.2 $\mathrm{mm}$ respective $0.24 \mathrm{~mm}$ thickness, which embed between them a layer of polypropylene (PP). This material shows remarkable proprieties such as flexural stiffness and very high lightness, which make it suitable for aeronautic and automotive industry [15].

The proprieties of the test samples made of Al-PP-Al (1.2 mm thickness) laminated material are presented in Table 1.

Table 1. Hylite properties [14]

\begin{tabular}{|c|c|}
\hline Weight & $1.8 \mathrm{~kg} / \mathrm{m}^{2}$ \\
\hline Maximum stretch & $22 \%$ \\
\hline Plain strain stretch & $18 \%$ \\
\hline Peel strength & $4 \mathrm{~N} / \mathrm{mm}$ \\
\hline Flexural stiffness & $7.1 \mathrm{kNmm}$ \\
\hline Aluminum yield point & $140 \mathrm{MPa}$ \\
\hline Aluminum tensile strength & $280 \mathrm{MPa}$ \\
\hline Expansion coefficient & $28^{*} 10^{-6} / \mathrm{K}$ \\
\hline
\end{tabular}

\section{Determination of mechanical characteristics and formability of the test samples}

\subsection{Uniaxial tensile test}

In this stage of the research, the strain hardening curve and other parameter of the material were determined by running the uniaxial tensile tests. As experimental layout, an Instron 5587machine and an ARAMIS optical measurement system were used. 
Figure 1. shows the experimentally determined hardening curve.

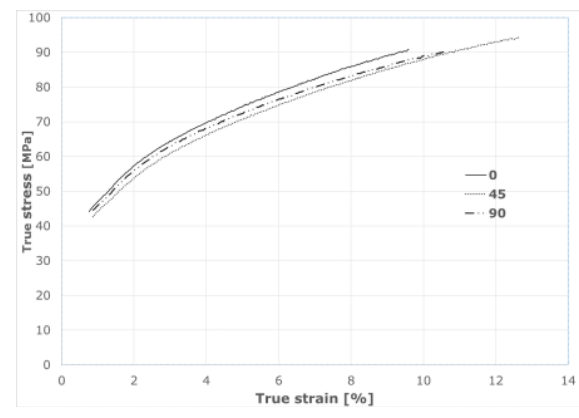

a. $\quad 1.2 \mathrm{~mm}$ laminated material

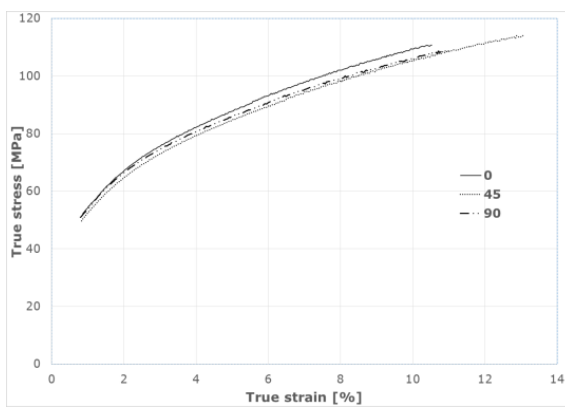

b. $\quad 1.4 \mathrm{~mm}$ laminated material

Fig. 1. The hardening curve

The Also, the plane anisotropy coefficients were determined, per SR ISO 10113:1996 standard, table 2 .

Table 2. Plastic anisotropy coefficients

\begin{tabular}{|c|c|c|}
\hline Material & $\begin{array}{c}\text { Cutting angle with respect to the } \\
\text { rolling direction [0] }\end{array}$ & Plastic anisotropy coefficients \\
\hline \multirow{3}{*}{$\begin{array}{c}1.2 \mathrm{~mm} \\
\text { composite }\end{array}$} & 0 & 1.06 \\
\cline { 2 - 3 } & 45 & 1.28 \\
\hline \multirow{3}{*}{$\begin{array}{c}1.4 \mathrm{~mm} \\
\text { composite }\end{array}$} & 90 & 1.09 \\
\cline { 2 - 3 } & 0 & 1.11 \\
\cline { 2 - 3 } & 45 & 1.32 \\
\hline
\end{tabular}

\subsection{Determination of the forming limit curves}

Nakajima test is widely used to obtain the forming limit curves for a given material. The test was performed on an experimental layout designed and built by the authors, using a hemispherical shape of the punch and a circular shape for the die. The Hasek samples proposed in 1978 were used. The state of stresses for this test is regarded as a combination between uniaxial tensile and echi-biaxial stretch. The data were gathered and processed by means of a data acquisition system. The ARAMIS measurement system was also included in the experimental chain. After running the test, the forming limit curves were determined. The obtained curves, for both thicknesses of the test samples used are shown in figure 2 .

Fig. 2. Forming limit curves

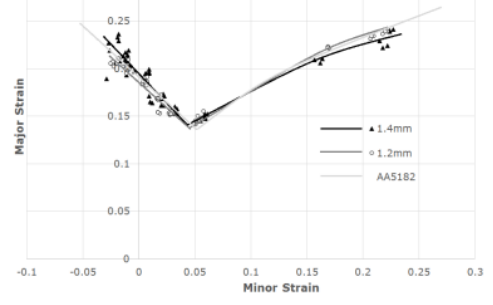




\subsection{Processing the parts by means of incremental forming}

As stated above, CNC milling machines are widely used for machining by means of incremental forming. For this research, a 3-axis vertical machining center was used. The considered tool was a hemispherical punch with a radius of $5 \mathrm{~mm}$ and the test samples were $120 \mathrm{~mm}$ squares. The incremental forming process was unfolded by driving the punch on the machining trajectories with $150 \mathrm{~mm} / \mathrm{min}$ (feed), while the rotational speed around its own axis was $150 \mathrm{rev} / \mathrm{min}$.

An off-line measuring process was used for strains and thickness reduction, by means of the ARGUS optical measurement system.

A cone-frustum shape was imposed for the part. The geometrical parameters for the cone-frustum were the following: diameter of the bases $45 \mathrm{~mm}$ and $4 \mathrm{~mm}$, slope angle $35^{\circ}$. $\mathrm{d}$. The processing trajectories were generated by intersecting the cone-frustum with parallel planes (all of them being also parallel with XOY plane, figure 3). The vertical distance between these planes, seen as the vertical increment was $1 \mathrm{~mm}$.
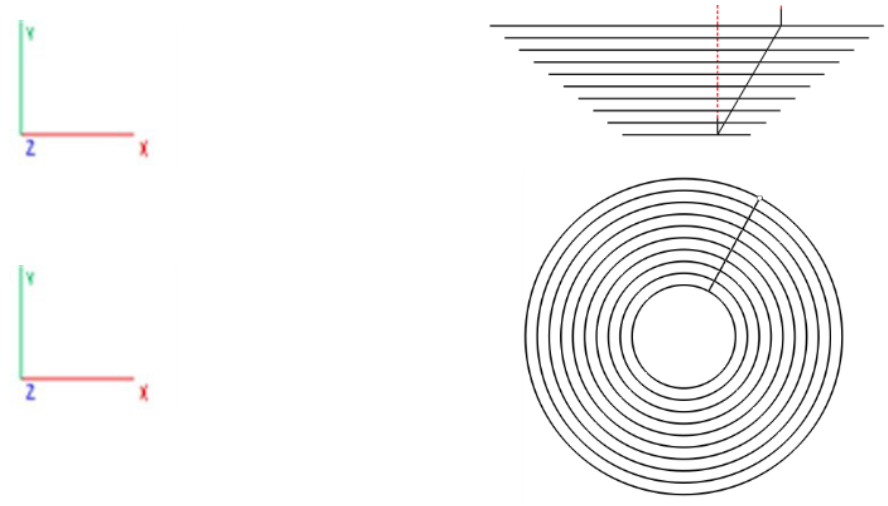

Fig. 3. Circular trajectory

The behavior of the part processed by single point incremental forming can be evaluated by measuring the distribution of the values of major and minor strains (Fig. 4, 5), the thickness reduction of the sample (Fig. 6) for the two sheets of workpiece.

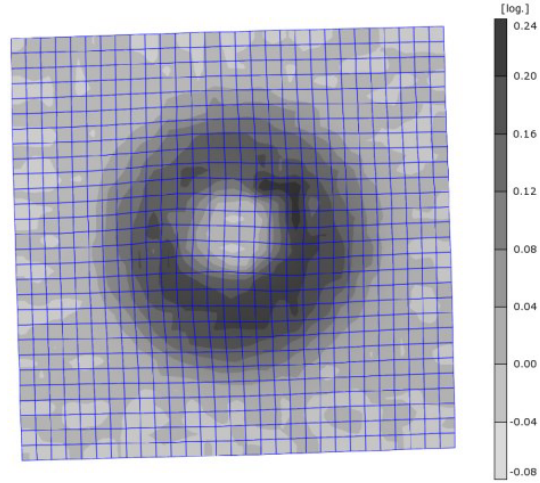

a. $\quad 1.2 \mathrm{~mm}$ laminated material

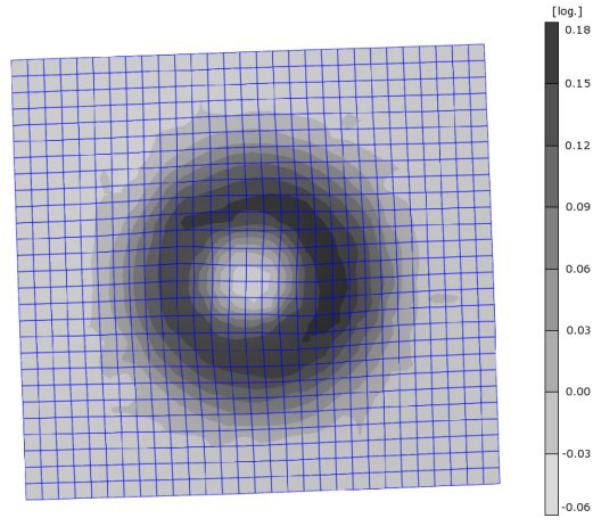

b. $\quad 1.4 \mathrm{~mm}$ laminated material

Fig. 4. Major strain distribution 
For the major strain, there is a homogenous distribution throughout the circumference of the pieces and shows a major strain at the start point of the every circle, in each plane. The maximum values of major principal strains are: 0.2377 for $1.2 \mathrm{~mm}$ laminated material respectively 0.1776 for $1.4 \mathrm{~mm}$ laminated material.

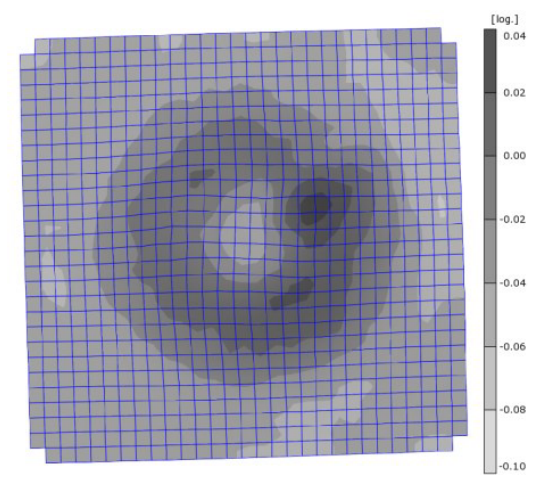

a. $\quad 1.2 \mathrm{~mm}$ laminated material

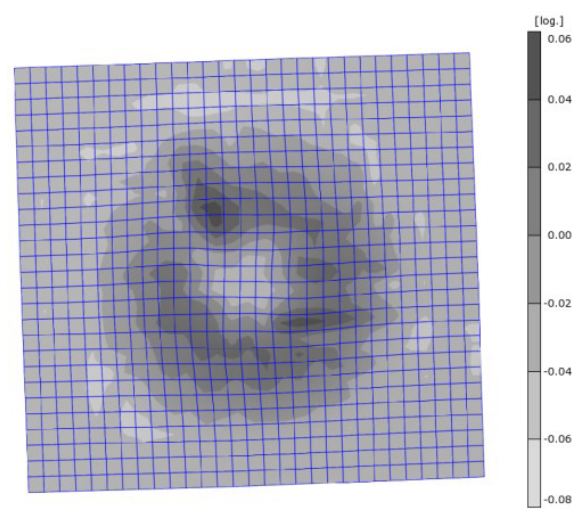

b. $\quad 1.4 \mathrm{~mm}$ laminated material

Fig. 5. Minor strain distribution

The minor strain distribution is similar to the major strain distribution. The values of minor strains are: 0.0421 for $1.2 \mathrm{~mm}$ laminated material respectively 0.0707 for $1.4 \mathrm{~mm}$ laminated material.

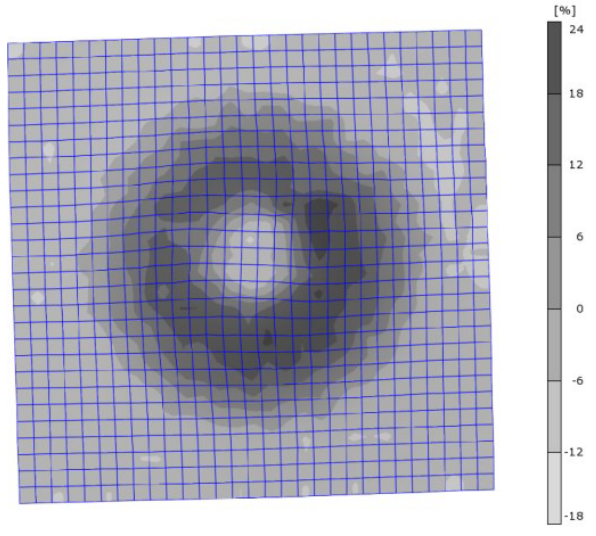

a. $\quad 1.2 \mathrm{~mm}$ laminated material

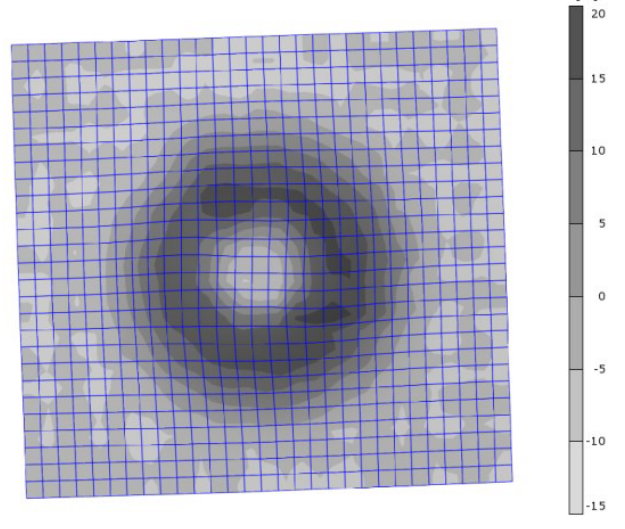

b. $\quad 1.4 \mathrm{~mm}$ laminated material

Fig. 6. Thickness of the specimen

For $1.2 \mathrm{~mm}$ laminated material reduction is $18.5 \%$ respectively $22.8 \%$ for $1.4 \mathrm{~mm}$ laminated material in the descent point of the last circular punch trajectory. In this case the work piece thickness reduction is not uniform distributed throughout its circumference.

\section{Conclusion}

The results of the researches have shown that laminated lightweight metallic materials have a good formability.

Single point incremental forming process of laminated material sheets $1.2 \mathrm{~mm}$ respectively $1.4 \mathrm{~mm}$ material were unfolded and the preliminary results have demonstrated 
that a proper selection of technological parameters (diameter of the punch, feed, speed) and processing trajectories can lead to parts with good structural and dimensional characteristics.

Further experimental tests will be performed in order to evaluate the influence of the geometry of the punches and the cutting parameters upon the surface roughness of the machined parts.

\section{References}

1. C. Girjob, O. Bologa, G. Racz, C. Biris, Applied Mechanics and Materials (760), 391-396 (2015)

2. J.A. DiCello, SAE, (800078), 1 (1980)

3. L.W. McKenna, M.H. Wohl, J.C. Woodbrey, (800079), SAE, 506 (1981)

4. T.S.V. Somoyajulu, Vibration and formability characteristics of aluminum-polymer sandwich materials, PhD Thesis, University of Michigan (2004)

5. B. Engel, J. Buhl, Metal Forming - Process, Tools, Design. (Edited by Mohsen Kazeminezhad, ISBN 978-953-51-0804-7, 2012)

6. A.L. Chicea, R.E. Breaz, 9th International Technology, Education and Development Conference INTED 2015Madrid, Spain, 3568-3574, (2015)

7. C. Biriș, Academic Journal of Manufacturing Engineering, (14), 2, pp. 33-39 (2016)

8. M. Tera, R.E. Breaz, O. Bologa, G. Racz, Proceedings in Manufacturing Systems, (9/2), ISSN 2067-9238, pp. 99-104 (2014)

9. R. Breaz, O. Bologa, M. Tera, G. Racz, The 14th Conference on Metal Forming, Krakow Poland, 427-430 2012

10. H. Chalal, S.G. Racz, T. Balan, International Journal of Mechanical Sciences, (59), 1, 104-114 (2012)

11. J. R. Duflou, A. Szekeres, and P. Vanherck, Advanced Materials Research, (6-8), 441-448 (2005)

12. R. Aerens, P. Eyckens, A. Van Bael, J. R. Duflou, International Journal of Advanced Manufacturing Technology, (46), Issue 9-12, 969-982 (2010)

13. M. Tera, R.E. Breaz, O. Bologa, S.G. Racz, Key Engineering Materials, (651), 1115-1121 (2015)

14. K.P. Jackson, J.M. Allwood, M. Landert, Journal of Materials Processing Technology (204), $290(2008)$

15. EAA (European Aluminum Association), The Aluminum Automotive Manual, http://www.eaa.net/aam (2002) 